\title{
Investigando as Ideias dos Alunos do Ensino Médio sobre a Matéria
}

\author{
Investigating the Ideas of High School Students over Matter
}

\author{
Simone A. A. Martorano'; Miriam Possar do Carmo²
}

\section{Resumo}

No ensino de Química, o conceito de Matéria é fundamental para que os alunos possam entender as transformações químicas que ocorrem entre diferentes materiais. Este trabalho apresenta os resultados de um estudo realizado com 180 estudantes do primeiro ano do Ensino Médio, de uma escola da rede particular de ensino, localizada na cidade de Santo André, no Estado de São Paulo. Procurou-se verificar quais seriam as ideias dos alunos, do ensino médio, sobre a matéria. Foi encontrado que poucos alunos relacionavam o termo matéria à ideia de partícula. A maior parte dos alunos, quando pensam em termos da química, relaciona a matéria a apenas as suas características macroscópicas.

Palavras-chave: Ensino de química, matéria, alunos ensino médio.

\begin{abstract}
In the teaching of chemistry, the concept of matter is essential for students to understand later, the chemical transformations that occurring between different materials. This paper presents the results of a study conducted with 180 students in the first year of high school, a private school located in the city of Santo André, in São Paulo. In this study we attempted to identify what are the students' ideas on the matter. It was found that few students relate the term to the idea of particle matter. Most students, when they think in terms of chemistry, the matter relates only to their macroscopic characteristics.

Key words: Teaching chemistry, matter, high school students.
\end{abstract}

1 Docente do Departamento de Ciências Exatas e da Terra, Universidade Federal de São Paulo. smartorano@yahoo.com

2 Aluna de doutorado do programa Interunidades em ensino de ciências, Universidade de São Paulo. mipcarmo@iq.usp.br 


\section{Introdução}

Comumente os professores de química do ensino médio consideram que seus alunos não conseguem aprender determinados conceitos químicos porque acreditam que eles iniciam o ensino médio com muitas falhas e lacunas de aprendizagem, como, por exemplo, dificuldades em interpretar gráficos, tabelas, dados experimentais, enunciados e exercícios ou ausência total desses conhecimentos.

Essas dificuldades são relatadas em muitas pesquisas (ADADAM,2012; IRVING; TRUNDLE, 2010; KIND, 2004; BENARROCH; MARÍN, 1998; TALANQUER, 2009) e, junte-se a elas, a dificuldade no entendimento de conceitos, como, por exemplo, em interpretar o comportamento da matéria em termos microscópicos (BENARROCH, 2000; LIU; LESNIAK, 2005; POZO, CRESPO, 2009). Segundo os autores, muitos indivíduos enfrentam dificuldades em entender a matéria como descontínua e de aplicar espontaneamente o modelo corpuscular em suas explicações, independentemente do grau de instrução recebida.

Contudo, o entendimento da natureza descontínua da matéria, como também o uso de um modelo corpuscular, são de fundamental importância para que os indivíduos compreendam as propriedades dos materiais e interpretem muitos fenômenos que ocorrem no mundo em que vivem, como, por exemplo, dissolução de sal (cloreto de sódio em água), corrosão do ferro, evaporação do álcool, escurecimento de um objeto de prata, condutibilidade elétrica dos metais, entre outros.

A Química como ciência, tem por objetivo o estudo de materiais, naturais ou sintéticos e as transformações químicas que eles possam sofrer, portanto, no ensino de Química, o conceito de Matéria é fundamental para que os alunos possam entender, mais adiante, as transformações químicas que ocorrem entres diferentes materiais. Segundo Pozo e Crespo (2009), uma parte importante dos conteúdos de química, principalmente no ensino médio, é dedicada a explicar a natureza e as propriedades da matéria e as mudanças que esta pode sofrer. Para os autores:

Os estudantes devem assumir que a matéria tem uma natureza descontínua, compreendendo que, para além da sua aparência visível ou dos diversos estados que pode apresentar, sempre é formada por átomos, pequenas partículas que estão em contínuo movimento e interação, que podem se combinar para dar lugar a estruturas mais complexas e entre as quais não existe absolutamente nada, o que implica a complexa e abstrata ideia de vazio" (POZO; CRESPO, 2009, p. 145).

Contudo, a aprendizagem das ciências, segundo Mortimer et al. (1999, p. 33):

[...] envolve ser iniciado nas formas científicas de se conhecer. As entidades e ideias científicas, que são construídas, validadas e comunicadas através das instituições culturais da ciência, dificilmente serão descobertas pelos indivíduos por meio de sua própria investigação empírica; aprender ciências, portanto, envolve ser iniciado nas ideias e práticas da comunidade científica e tornar essas ideias e práticas significativas no nível individual.

Sendo assim, segundo os autores, o papel do professor de ciências, mais do que organizar o processo pelo qual os indivíduos geram significados sobre o mundo natural, seria o de atuar como mediador entre o conhecimento científico e os aprendizes. Sem essa mediação dificilmente o aluno construiria o conceito de matéria.

Acreditamos que ao cursar o primeiro ano do ensino médio os alunos já possuam algumas ideias sobre a constituição da matéria, que são formadas, principalmente, pelo contato com os diferentes materiais no seu dia-a-dia. As informações que estes alunos recebem de varias fontes, como da mídia, contato com colegas e familiares, também podem influenciar na formação desse conceito.

Segundo Carmo e Marcondes (2008) é importante que o professor conheça as concepções prévias dos alunos, uma vez que estas estabelecerão conexões entre os conceitos não somente com os já existentes, como com os advindos de novas informações e de novas relações sociais, o que requer por parte do aluno uma atividade mental. 
Se considerarmos que os alunos constroem um conhecimento novo a partir de conhecimentos que ele já possui (POZO e CRESPO, 2009), é importante então que o professor leve em consideração as ideias prévias que eles possuem sobre o conceito Matéria, na hora de planejar a sua estratégia de ensino.

Matéria, termo difícil de ser definido com precisão. No entanto, uma definição operacional é a de que se trata de qualquer coisa que tem massa e ocupa lugar no espaço, tais como: ouro, água, ar, alimentos, substância, mistura de substâncias, etc. Do ponto de vista científico, a matéria é corpuscular e descontínua, formada por partículas que podem mover-se, combinar umas com as outras, formando estruturas mais complexas, não existindo entre elas, absolutamente nada, o que implica a complexa e abstrata ideia de vazio (POZO; CRESPO, 2009).

Assim, na Química a matéria é descrita como formada por átomos, os quais ao combinar-se entre si formam as moléculas, ou ainda se agrupam em elementos. Os átomos por sua vez, estão formados por partículas ainda menores, caracterizadas como prótons, nêutrons e elétrons além de outras submicroscópicas.

Do ponto de vista histórico, já com os filósofos gregos foram dadas interpretações à matéria considerando a existência de átomos individuais movendo-se através do vazio. Aristóteles considerava a matéria contínua e formada por quatro elementos: ar, água, terra e fogo e mais tarde, veio a citar um quinto elemento que denominou de éter. Não admitia à ideia de vazio e de descontinuidade da matéria, o que ao longo da história influenciou na dificuldade da construção do modelo corpuscular da matéria.

No ensino de química, a concepção de continuidade da matéria constitui para os alunos, do ensino médio, um obstáculo para a elaboração de outros conceitos pertinentes à química, tais como: compreensão da estrutura da matéria nos seus diversos estados físicos, bem como propriedades como a dissolução, e a interpretação das transformações que ocorrem com a matéria do ponto de vista químico (reações químicas).

Desta forma, o aluno precisa elaborar a noção de que a matéria tem uma natureza descontínua, e mais do que seu aspecto visível, ou dos diversos estados em que ela se apresenta (sólido, líquido, gasoso) é sempre formada por átomos, pequenas partículas que se encontram em contínuo movimento e interação.

Portanto, o objetivo desse estudo foi o de verificar quais seriam as ideias prévias dos alunos, do ensino médio, sobre matéria. A hipótese deste é a de que os alunos, mesmo antes da instrução formal já possuem ideias relacionadas a esse conceito.

\section{Ideias dos alunos em relação à estrutura e natureza particular da matéria}

Ao revisarmos diversos estudos bibliográficos encontramos algumas ideias dos alunos em relação à estrutura e natureza particular da matéria.

Segundo Treagust (2002), os estudantes acreditam que as partículas, que constituem a matéria, estão em contato umas com as outras, não existindo espaço vazio entre elas. De acordo com o autor, essa ideia é consistente com a máxima de Aristóteles "a natureza abomina o vácuo".

Em Talanquer (2009) encontramos, por exemplo, a ideia de que os objetos físicos são sólidos e movimentam-se de forma contínua, o que também pode ser verificado nos estudos de Adadam (2012). Esta crença pode dificultar a construção de concepções sobre a descontinuidade da matéria. Segundo Talanquer(2009) os alunos em vários níveis de escolaridade, não acreditam na noção de espaços vazios entre as partículas constituintes da matéria e atribuem propriedades macroscópicas as partículas, tais como: átomos e moléculas se expandem ao serem aquecidos, ou ainda, as moléculas têm a mesma densidade e cor da substância real.

De acordo com a ampla revisão realizada por Kind (2004), para documentar as principais 
concepções alternativas sobre vários conceitos da química, 25\% de estudantes, de diferentes idades, utilizam em suas respostas a ideia de matéria contínua. Crianças, normalmente, utilizam o critério "ver para crer", para identificar se algo é matéria ou não. Por exemplo, os gases não são identificados como sendo matéria porque são invisíveis.

As ideias de crianças sobre as propriedades da matéria também foram estudadas por Piaget e Inhelder, segundo Kind (2004), eles identificaram, em seus estudos, as seguintes ideias ingênuas das crianças sobre matéria:

- A matéria não possui aspecto permanente. Quando a matéria desaparece, por exemplo, na dissolução quando dissolvemos açúcar na água.

- A matéria tem uma essência materialista. A matéria pode "desaparecer", contudo suas propriedades (como o sabor) podem continuar a existir completamente independente de sua existência.

- Peso não é uma propriedade intrínseca da matéria. A existência de matéria sem peso pode ser aceita.

Ainda, podemos encontrar nos estudos de Treagust, (2002), algumas dificuldades em relação ao entendimento, por parte dos alunos, da estrutura da matéria, tais como:

- A matéria é tal como a vêem, estática e contínua;

- Apresentam dificuldades de interpretar e utilizar o modelo corpuscular da matéria.

- Atribuem às partículas, propriedades similares as do sistema a que as contém, ou seja, surgem concepções de que quando a matéria sofre modificações suas partículas experimentam o mesmo tipo de modificação (dilatação, evaporação, cor, aspecto, estado físico etc.). Atribuem propriedades às partículas que a matéria apresenta no mundo macroscópico.

- Consideram que as partículas são formadas de pequenos grãos, que só se movem e se agitam dependente de um agente externo (a chama, corrente de ar, etc.).

Podemos verificar, com base nestes trabalhos, que os alunos interpretam a estrutura da matéria, a partir das propriedades macroscópicas da mesma, com ideias cercadas de um mundo real e pouco utilizam o modelo científico em suas explicações. Raras vezes empregam ideias relativas à descontinuidade da matéria e os conhecimentos de química, em suas argumentações, são dificilmente explorados, e quando o fazem, mesclam as concepções proporcionadas pela escola com as ideias prévias (POZO; CRESPO, 2009).

Segundo esses autores, existe a possibilidade da coexistência de diversas teorias, possibilitando aos alunos transitarem entre suas explicações em termos de partículas constituintes da matéria e em explicações macroscópicas as quais envolvem a aparência observável da matéria.

Outro aspecto a ser considerado é o entendimento sobre o significado da palavra matéria. Segundo Langer (1971) à medida que uma palavra (tomamos no nosso caso o exemplo: matéria) vai sendo usada, ambos, o abstrato e o concreto parecem pertencer um ao outro.

Por outro lado, se considerarmos a função da linguagem como um sistema básico da comunicação, podemos comentar que a palavra, além da função denotativa e comunicativa, apresenta a função conotativa, de forma a exprimir significados diferentes dependendo do contexto em que foi utilizada (APOSTÓLICO, 2004).

Antes de ser expresso em palavras, o pensamento tende a relacionar as ideias entre si, estabelecendo conexões com os conceitos que fazem parte do repertório conhecido.

Portanto, a palavra matéria, passa a ser usada com significados diferentes e até mesmo tornandose um obstáculo à aprendizagem de ciência. 


\section{Teoria de Conceitos: Visão Teórica}

Segundo Lomônaco (1997), aquilo que o sujeito conhece delimita fortemente como ele aprende um novo conceito.

A formação de um conceito na visão teórica é vista como parte de uma rede de relações com outros conceitos e não de forma isolada. Essa rede relações é denominada teoria. Nesta visão, quando um novo conceito é aprendido, a nova representação se liga ao conhecimento que o sujeito já possui. Portanto, o sujeito não é mais visto como uma "folha em branco".

Acreditamos nesse trabalho, que os alunos antes de passarem pelo ensino médio os alunos já possuíam concepções sobre a matéria, assim como ideias sobre como ela pode se apresentar (sólido, liquido e gasoso).

\section{Metodologia}

Participaram desse estudo, 180 estudantes do primeiro ano do Ensino Médio, de uma escola da rede particular de ensino, localizada na cidade de Santo André, no estado de São Paulo. O instrumento de coleta de dados, foi aplicado no final do primeiro trimestre de 2009.

Cada aluno recebeu uma folha (Anexo I), informando seus dados pessoais e instruções para a realização da tarefa pedida.

A aplicação do instrumento foi feita em sala de aula por uma das pesquisadoras. Os alunos foram informados a respeito do propósito da pesquisa e todos concordaram em participar. Realizaram a atividade em 15 minutos.

Todas as respostas dos alunos à palavra "Matéria" foram digitadas e organizadas em ordem alfabética. A lista de repostas foi, então, lida diversas vezes pelas pesquisadoras, com o objetivo de identificar aspectos comuns que possibilitariam a criação das categorias para o agrupamento dos dados.

A formação das categorias, conforme pode ser observado no Quadro 1, foi o resultado do consenso, entre as pesquisadoras, sobre qual item deveria ou não ser incluído em determinada categoria. Os itens que não pertenciam a nenhuma das categorias elaboradas foram agrupados na categoria "outros".

Seguindo-se a orientação de Lomônaco, Cazeiro e Ferreira (2006), adotou-se como critério de elaboração de categoria o fato de englobar, no mínimo, $5 \%$ do total de respostas dos alunos que participaram desse trabalho.

Após a elaboração das categorias, estas foram utilizadas para agrupar as respostas dos alunos e para computar a frequência em que elas apareciam e o percentual de cada uma das categorias criadas para a palavra "Matéria".

Quadro 1. Categorias elaboradas a partir das respostas dos alunos em relação ao significado da palavra matéria.

\section{MATÉRIA}

A) AMBIENTE ESCOLAR/DISCIPLINAS/

TEORIAS: Engloba termos referentes a aspectos relacionados ao ambiente da escola em que o aluno está inserido (exemplos: "aluno", "aula", "apostila", "giz", "sala de aula"). Aspectos relacionados aos conteúdos, conhecimentos, e teorias ensinados e utilizadas em sala de aula pelo professor (exemplos: "química", "física", "biologia").

B) SUBSTÂNCIAS/MISTURA/PARTÍCULAS: engloba termos referentes a formas particulares de representação da matéria, abrangendo ideias submicroscópicas (exemplos: "átomo", "moléculas") e macroscópicas (exemplos: "água", "ar", "alimento")

C) CARACTERÍSTICAS DA MATÉRIA: MATÉRIA/CONCRETO/DIMENSÃO/ PROPRIEDADES DA MATÉRIA/ESTADOS FÍSICOS: Engloba todos os termos que de alguma forma tendem a caracterizar a matéria, tais como; definições do que é matéria (exemplos: "é tudo que ocupa lugar no espaço", "algo que podemos tocar, sentir a massa"), dimensões (ex.: "quantidade", "tamanho", "volume") e propriedades físicas (ex: "estado físico; sólido líquido e gasoso", "opaco", "duro", "leve", entre outros). 
D) OBJETOS/ EQUIPAMENTOS: engloba termos que se referem a exemplos de matéria, que sofreram alguma modificação dada a ação do homem, a fim de se tornarem úteis. (exemplos: "bola", "caixa", "microscópico", "algo que existe e pode ser tocado").

E) SERESVIVOS/SENTIDOS/

PROCESSOSPSICOLÓGICOS /PROFISSÕES:

Engloba termos que se referem a existência de vida (ser humano, vida), a processos psicológicos desempenhados por estes seres vivos (ex.:"aprendizagem", "raciocínio"), profissões (ex: "cientista", "astronauta"), que podem utilizar seus sentidos(ex.:"cheiro", "visível”).

F) OUTROS: qualquer outro tipo de resposta não classificada nas categorias acima.

Fonte: Autor

\section{Resultados e Discussões}

No quadro 2 encontram-se os valores porcentuais das respostas dos alunos para cada categoria elaborada.

Quadro 2. Porcentagem de respostas em cada uma das categorias em relação ao entendimento dos 180 alunos sobre o termo "matéria".

\begin{tabular}{|l|c|}
\hline CATEGORIA & $\begin{array}{c}\text { Respostas } \\
\mathbf{( \% )}\end{array}$ \\
\hline $\begin{array}{l}\text { Ambiente Escolar/Disciplinas/ } \\
\text { Teorias }\end{array}$ & $51,35 \%$ \\
\hline Substâncias/Mistura /Partículas & $12,92 \%$ \\
\hline $\begin{array}{l}\text { Características da Matéria } \\
\text { (Matéria/Concreto/Estados Físicos/ } \\
\text { Propriedades Da Matéria/Dimensão }\end{array}$ & $17,39 \%$ \\
\hline Objetos/ Equipamentos & $6,25 \%$ \\
\hline $\begin{array}{l}\text { Seres Vivos/Sentidos/Processos } \\
\text { Psicológicos/Profissões }\end{array}$ & $6,25 \%$ \\
\hline Outros & $5,84 \%$ \\
\hline
\end{tabular}

Fonte: Autor

Observamos no quadro acima que a maior parte dos alunos $(51,35 \%)$ relaciona o termo matéria à ideia de ambiente escolar, incluindo também as disciplinas escolares e o conteúdo que é ensinado (teorias), pertencentes a categoria: ambiente escolar/ disciplinas/teorias.

Podemos verificar, com estes dados que, apesar do teste ter sido aplicado em uma aula de química, o aluno ao ser submetido ao mesmo teve um tempo reduzido para explorar suas próprias ideias em relação ao conceito de matéria do ponto de vista científico. Nas suas respostas prevaleceram ideias relacionadas à sua experiência escolar, ou seja, o contato com as disciplinas escolares e o conteúdo das mesmas.

O aluno, ao realizar relações de similaridade, pode ter tido por trás uma teoria (senso comum), a qual deriva do conhecimento de mundo a seleção dos atributos que para eles eram importantes, relevantes e confiáveis.

Para Apostólico (2004), o pensamento tende a relacionar uma coisa com outras, estabelecendo conexões não apenas com o conceito científico da palavra, mas com uma teia de relações que ele estabelece com seu contexto, ou seja, com os conceitos que fazem parte de um repertório conhecido.

Embora considerando que o aluno, nesta tarefa, não tenha tido tempo de organizar suas ideias sobre a palavra matéria do ponto de vista científico, ele pode ter acionado concepções prévias já existentes de sua estrutura cognitiva. Desta forma, o reconhecimento das ideias já estabelecidas na mente do aluno se torna um fator importante para que se estabeleçam ligações entre o que pretendemos ensinar e o que o aluno já conhece.

Segundo Carmo e Marcondes (2008), estas pré-concepções ou ideias de senso comum, são representações que cada indivíduo faz do mundo que o cerca e podem variar de significado de uma situação para outra. Podem ser elaboradas através da interação do sujeito com o mundo. 
Todavia estas ideias de senso comum podem ser inibidoras da construção de conceitos, pois, são altamente estáveis, resistentes a mudanças, pois para cada indivíduo, são úteis e coerentes.

Portanto, a palavra matéria pode ser usada com significados diferentes e até mesmo tornando-se um obstáculo à aprendizagem do conceito científico.

Somente $17,39 \%$ do total das respostas estão relacionadas ao termo matéria incluídas na categoria: características da matéria (matéria/ concreto/dimensão/propriedades da matéria/estados físicos).

Neste caso, percebemos a predominância de atributos macroscópicos, nas palavras e frases dadas pelos alunos, embora suas proposições se aproximassem mais ao conceito operacional de matéria. Os alunos interpretaram a matéria com base em propriedades macroscópicas, provavelmente com ideias cercadas de um mundo real, com base naquilo que podem ver, (KIND, 2004). Pouco se utilizaram de um modelo científico em suas explicações e ideias sobre a descontinuidade da matéria não são atribuídas por eles nesta categoria. No entanto, notamos nesta categoria que já começa a surgir no pensamento do aluno uma compreensão melhor do conhecimento em um domínio específico, pois suas respostas passam a considerar o conceito da matéria em nível maior de profundidade, embora ainda em um plano do observável.

Percebe-se nesta categoria, que as respostas dadas pelos alunos, apresentaram conexões com conceitos mais estruturados sobre a matéria, o que nos leva a inferir que existem concepções mais elaboradas em suas estruturas cognitivas, como ideias sobre os estados físicos da matéria (sólido, liquido e gasoso). Segundo Pozo e Crespo (2009), isto não implica que os alunos se encontrem em um nível de compreensão microscópico sobre o conceito de matéria, pois no geral suas respostas estão associadas mais a uma visão macroscópica.

$\mathrm{Na}$ categoria: substância/mistura/partículas, encontramos $12,92 \%$ das respostas dos alunos, as quais abrangem ideias submicroscópicas relacionadas ao conceito de matéria, tais como: átomos, elementos, moléculas, o que não implica que tenham um domínio sobre a concepção de descontinuidade. No entanto, começam a utilizar elementos em suas explicações, derivados do ensino formal de química, o que implica no nosso ponto de vista que estes alunos estão se afastando de suas ideias imediatas.

\section{Comentários Finais}

O significado da palavra matéria relacionado ao contexto do aluno, no caso o contexto escolar, parece ter influenciado significativamente a expressão de suas ideias sobre esta palavra e, não o significado da mesma no contexto de uma aula de química.

Ideias manifestadas de acordo com as características das propriedades e estrutura da matéria foram pouco acionadas pelos alunos. A partir da análise das ideias dos alunos sobre a matéria, podemos supor que o ensino deveria proporcionar aos alunos modelos alternativos de representação deste mundo submicroscópico que sustentem o nível de abstração destes alunos da transição de um mundo macroscópico ao submicroscópico, caso contrário, os mesmos podem não conseguir estabelecer novas relações e não construírem o conceito científico sobre a matéria.

Os alunos costumam interpretar os fenômenos com base em um realismo ingênuo, para os quais, "as coisas são de certa forma porque são assim". A mudança em suas crenças exigirá a integração de conhecimentos em níveis cada vez mais complexos. Assim, aceitar um modelo de descontinuidade da matéria exige muita abstração e não é fácil para os alunos. Para tal, um ensino visando o desenvolvimento de ideias sobre a estrutura da matéria deve ser planejado através de vários tipos de representações com exigências cognitivas cada vez mais elaboradas para que o aluno manifeste ideias também mais elaboradas. 


\section{Referências}

ADADAN, E. Using Multiple Representations to promote Grade 11 Student's Scientific Understanding of the Particle Theory of Matter. Research Science Education, 2012.

APOSTÓliCO, M. C. L. A linguagem escrita do livro didático de ciências de $8^{a}$ série do ensino fundamental. 2004. Dissertação (Mestrado em Ensino de Ciências) Universidade de São Paulo, São Paulo.

BENARROCH, B. A. El desarrollo cognoscitivo de los estudiantes en el área de la natureza corpuscular de la matéria. Enseñanza de Las Ciencias, Barcelona, v. 18, n. 2, p. 235-246, 2000.

BENARROCH, B. A.; MARÍN, M. N. Dependencia de las explicaciones de los alumnos de esquemas de conocimiento especifícos y generales. In: HERNÁNDEZ, E. B.; PRO BUENO, A. J. Investigación e innovación en la enseñanza de las ciencias. España: DM. p. 67-75. 1998.

CARMO, M. P.; MARCONDES, M. E. R., Abordando soluções em sala de aula: uma experiência de ensino a partir das ideias dos alunos. Química Nova na Escola, São Paulo, n. 28, p. 37-41, maio 2008.

KIND, V. Beyond appearances: student's misconceptions about basic chemical ideas. 2. ed. Durham: School of Education, Durham University, 2004.

LIU, X.; LESNIAK, K. Student's Progression of understanding the matter concept from elementary to high school. Science Education, Salem, v. 89, n. 3, p. 433-450, 2005.

LOMÔNACO, J. F. B. A natureza dos conceitos: visões psicológicas. 1997. Tese (Livre Docência) - Instituto de Psicologia, Universidade de São Paulo, São Paulo.

LOMÔNACO, J. F. B.; CAZEIRO, A. P. M.; FERREIRA, A. M. Concepções de deficiência e reabilitação: um estudo exploratório com graduados em fisioterapia. Revista Semestral da Associação Brasileira de Psicologia escolar e Educacional, São Paulo, v. 10, n. 1, p. 83-97, jan./jun. 2006.

MORTIMER, E.; DRIVER, R.; ASOKO, H.; LEACH, J.; SCOTT, P. Construindo conhecimento científico na sala de aula.Química Nova na Escola, São Paulo, v. 9, p. 33-40.1999.

POZO, J. I.; CRESPO, M. A. G. A aprendizagem $e$ o ensino de ciências. do conhecimento cotidiano ao conhecimento cientifico. 5. ed. São Paulo: Artmed. p. 138-150, 2009.
TALANQUER, V. On cognitive constraints and learning progressions: the case of "structure of matter". International Journal of Science Education. London, v. 4, n. 15, p. 2123-2136, 2009.

TREAGUST, D. F. The particulate nature of matter: challenges in understanding the submicroscopic word. In: GILBERT, J. K. (Ed.). Chemical education: towards research-based practice. Local: The Netherlands, Kluwer Academic Publishers, 2002. p. 189-212.

\section{ANEXO 1 - Instrução para os alunos da
folha da atividade sobre o entendimento do \\ ANEXO 1 - Instrução para os alunos da
folha da atividade sobre o entendimento do termo matéria.}

\author{
Nome:

Unidade Escolar:
Sexo: \\ Instruções \\ Estamos interessados em conhecer as ideias comumente associadas ao termo \\ MATÉRIA. Assim sendo, venho solicitar sua colaboração neste trabalho de pesquisa. \\ Na parte superior da página seguinte, você encontrará a palavra MATÉRIA. O que lhes \\ pedimos é muito simples: leia a palavra e, a seguir, no período de um minuto e meio, \\ escreva no espaço em branco tudo o que lhe vier à mente diante deste estímulo. A sua \\ primeira impressão é muito importante; portanto, você não deve se preocupar em saber \\ se suas respostas são adequadas ou não. O que nos interessa fundamentalmente são suas \\ associações ou evocações diante do estímulo apresentado.
}

Recebido em 17 Setembro 2012 - Received on September 17, 2012. Aceito em 17 Junho, 2013 - Accepted on June 17, 2013. 